\title{
LHomme
}

L'HOMME Revue française d'anthropologie

$183 \mid 2007$

Comment être parents ?

\section{Tarabai Shinde, Comparaison entre les femmes et les hommes}

Trad. du marathi par Madhuri Purandare et Nandita Wagle. Préface de Martine Van Woerkens. Paris, Indigo \& Côté-femmes, 2005, 115 p., bibl.

Véronique Bouillier

\section{(2) OpenEdition Journals}

Édition électronique

URL : http://journals.openedition.org//homme/9931

DOI : 10.4000//homme.9931

ISSN : 1953-8103

Éditeur

Éditions de l'EHESS

Édition imprimée

Date de publication : 1 septembre 2007

Pagination : 253-254

ISSN : 0439-4216

Référence électronique

Véronique Bouillier, "Tarabai Shinde, Comparaison entre les femmes et les hommes », L'Homme [En ligne], 183 | 2007, mis en ligne le 28 juin 2007, consulté le 24 septembre 2020. URL : http:// journals.openedition.org//homme/9931; DOI : https://doi.org/10.4000//homme.9931

Ce document a été généré automatiquement le 24 septembre 2020

〔c École des hautes études en sciences sociales 


\section{Tarabai Shinde, Comparaison entre les femmes et les hommes}

Trad. du marathi par Madhuri Purandare et Nandita Wagle. Préface de Martine Van Woerkens. Paris, Indigo \& Côté-femmes, 2005, 115 p., bibl.

\section{Véronique Bouillier}

1 PUBLIÉ EN 1882, ce court texte d'une jeune femme marathe nous saisit aujourd'hui encore par la liberté et la véhémence de son propos et de son style. Cuuvre unique d'une auteur dont on ne sait presque rien, elle fut redécouverte ces dernières années par les mouvements féministes indiens attentifs à l'émergence d'une littérature féminine réformiste ou contestataire, et fut traduit et édité en anglais en 1994 par Rosalind O’Hanlon.

2 La riche préface de Martine Van Woerkens situe cette œuvre dans son contexte en la comparant avec deux autres écrits féminins issus des mêmes milieux réformateurs: The High Caste Hindu Woman de Pandita Sarasvati (en 1887) et les Mémoires de notre vie ensemble de Ramabai Ranade (en 1910). Toutes deux dénoncent la condition faite aux femmes dans la religion traditionnelle, mais plus encore dans les coutumes contemporaines, l'ouvrage de Pandita Sarasvati étant davantage un essai explicatif et démonstratif et celui de Ramabai Ranade un récit autobiographique ancré sur les heurts et malheurs de sa relation à son époux, le célèbre réformateur Justice Ranade. Paru quelques années auparavant, le texte de Tarabai Shinde tranche par sa violence et sa passion : apostrophant les hommes, haranguant les dieux, elle manie l'ironie et la provocation et ne s'arrête pas aux contradictions. Irrévérencieuse, se moquant des textes sacrés et des figures convenues du panthéon, elle n'hésite pas à les invoquer pour exalter le motif traditionnel du pouvoir féminin ou shakti. Décrivant un univers social profondément vicié, elle stigmatise l'hypocrisie et la bassesse des hommes en termes fréquemment haineux («ces tigres à l'apparence humaine, aveuglés de convoitise, complètement ivres d'alcool, aux corps gonflés d'avoir consommé trop de viande, ces milliers d'hommes bêtes" [p. 72], "quel chacal roublard vous êtes!» [p. 67], ou encore "on pourrait parler à l'infini de vos fourberies» [p. 89]). Cette dénonciation du sort fait aux femmes l'amène à avoir une position ambivalente face au 
colonialisme : tout en raillant les Indiens anglicisés vus comme de serviles imitateurs, elle chante néanmoins les louanges des colonisateurs ("Que Dieu fasse durer éternellement le règne des Britanniques, car grâce à leur règne les femmes ont bénéficié d'éducation» [p.67]). Ce qu'elle reproche à ces derniers c'est leur refus d'intervenir dans les domaines socioreligieux : «Pourquoi un gouvernement qui a fait tant de choses pour votre bien-être ne se mêlerait-il pas de vos affaires pour délivrer les faibles femmes des tourments imposés par votre religion creuse? » (p. 71).

3 Avec son style tout en rupture de tons, parfois populaire, spontané, cru, parfois savant, littéraire jusqu'à l'alambiqué, que la traduction rend habilement (malgré certains anachronismes qui surprennent), la diatribe de Tarabai Shinde et sa contextualisation par la préface de Martine Van Woerkens donnent accès à un univers culturel où à la violence oppressive de la tradition répond la virulence de sa dénonciation. On y retrouve la liberté de parole de ce qu'on connaît au Maharashtra sous le nom de " chants de la meule », chants de femmes volontiers satiriques ou revendicatifs.

\section{AUTEUR}

\section{VÉRONIQUE BOUILLIER}

EHESS, Centre d'études de l'Inde et de l'Asie du Sud, Paris.

bouillier@ehess.fr 